\title{
Effect of chemical processing on physical properties of hemp (Cannabis sativa) fibres
}

AMRITA SINGH AND MANISHA GAHLOT

Received: 01.09.2014; Revised: 09.11.2014; Accepted: 24.11 .2014

See end of the paper for authors' affiliations

\section{AMRITA SINGH}

Department of Clothing and Textiles, College of Home Science, G.B. Pant University of Agriculture and Technology, Pantnagar, UDHAM SINGH NAGAR (UTTARAKHAND) INDIA

Email: amrita.textile07@gmail. com
ABSTRACT : Chemical processing is essential for proper separation of individual bast fibres from fibre bundles. Hemp fibres were subjected to different scouring agents and their effect on tensile strength, elongation, fibre fineness and per cent fibre weight loss was studied. Alkalis were found effective in improvement of fineness but alkali scoured fibres exhibited less tensile strength in comparison to acid scoured fibres. Fibres of selected scouring method were bleached to improve their appearance, colour and softness. After each chemical processing, fibre fineness and whiteness value increased but tensile strength and elongation decreased gradually.

KEY WORDS: Hemp fibres, Retting, Scouring, Bleaching

- HOW TO CITE THIS PAPER : Singh, Amrita and Gahlot, Manisha (2014). Effect of chemical processing on physical properties of hemp (Cannabis sativa) fibres. Asian J. Home Sci., 9 (2) : 550-554. 